\title{
BMJ Open Causes of and contributors to infant mortality in a rural community of North India: evidence from verbal and social autopsy
}

\author{
Sanjay Kumar Rai, ${ }^{1,2}$ Shashi Kant, ${ }^{1,2}$ Rahul Srivastava, ${ }^{3}$ Priti Gupta, ${ }^{4}$ \\ Puneet Misra, ${ }^{1,2}$ Chandrakant Sambhaji Pandav, ${ }^{1}$ Arvind Kumar Singh ${ }^{5}$
}

To cite: Rai SK, Kant S, Srivastava R, et al. Causes of and contributors to infant mortality in a rural community of North India: evidence from verbal and social autopsy. BMJ Open 2017;7:e012856. doi:10.1136/ bmjopen-2016-012856

- Prepublication history and additional material are available. To view these files please visit the journal online (http://dx.doi. org/10.1136/bmjopen-2016012856).

Received 4 June 2016 Revised 8 December 2016 Accepted 17 January 2017

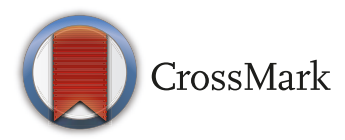

${ }^{1}$ Centre for Community Medicine, All India Institute of Medical Sciences, New Delhi, India

${ }^{2}$ INDEPTH Network, Accra, Ghana

${ }^{3}$ Independent researcher, New Delhi, India

${ }^{4}$ Centre for Chronic Disease Control, Gurgaon, India

${ }^{5}$ Department of Community and Family Medicine, All India Institute of Medical Sciences, Bhubaneswar, Odisha, India

Correspondence to Dr Arvind Kumar Singh; arvind28aug@gmail.com

\section{ABSTRACT}

Objective To identify the medical causes of death and contribution of non-biological factors towards infant mortality by a retrospective analysis of routinely collected data using verbal and social autopsy tools.

Setting The study site was Health and Demographic Surveillance System (HDSS), Ballabgarh, North India Participants All infant deaths during the years 20082012 were included for verbal autopsy and infant deaths from July 2012 to December 2012 were included for social autopsy.

Outcome measures Cause of death ascertained by a validated verbal autopsy tool and level of delay based on a three-delay model using the INDEPTH social autopsy tool were the main outcome measures. The level of delay was defined as follows: level 1, delay in identification of danger signs and decision making to seek care; level 2, delay in reaching a health facility from home; level 3 , delay in getting healthcare at the health facility.

Results The infant mortality rate during the study period was $46.5 / 1000$ live births. Neonatal deaths contributed to $54.3 \%$ of infant deaths and $39 \%$ occurred on the first day of life. Birth asphyxia $(31.5 \%)$ followed by low birth weight (LBW)/prematurity $(26.5 \%)$ were the most common causes of neonatal death, while infection $(57.8 \%)$ was the most common cause of post-neonatal death. Care-seeking was delayed among $50 \%$ of neonatal deaths and $41.2 \%$ of post-neonatal deaths. Delay at level 1 was most common and occurred in $32.4 \%$ of neonatal deaths and $29.4 \%$ of post-neonatal deaths. Deaths due to LBW/prematurity were mostly followed by delay at level 1 .

Conclusion A high proportion of preventable infant mortality still exists in an area which is under continuous health and demographic surveillance. There is a need to enhance home-based preventive care to enable the mother to identify and respond to danger signs. Verbal autopsy and social autopsy could be routinely done to guide policy interventions aimed at reduction of infant mortality.

\section{INTRODUCTION}

The global reduction in mortality of children aged $<5$ years between 1990 and 2015 was $53 \%$ against the aim of a two-thirds reduction
Strengths and limitations of study

- A validated verbal autopsy tool was used to ascertain the cause of death.

- This study presents, for the first time from India, results of both verbal and social autopsy to capture the entire spectrum of medical causes and social contributors of infant mortality.

- Social autopsy data are presented only for a 6-month period, which is likely to result in a large variation in the estimation of delay. The inherent limitations of verbal and social autopsy need to be considered with caution.

by Millennium Development Goals. ${ }^{1}$ The UN inter-agency group for under five mortality estimation reports an almost constant annual rate of reduction in south-east Asia during this period. The proportional contribution of infant deaths to overall child mortality has increased over the years and has reached $73 \%$, so it is important to target this period of life. ${ }^{12}$ The Sample Registration System (SRS) of India reported a decline in the infant mortality rate (IMR) from $72 / 1000$ live births in 1998 to $57 / 1000$ live births in 2006, which further declined to 39/1000 live births in $2014 .^{3-5}$ Moreover, in rural India where the majority of births take place, the IMR is significantly higher than in urban areas. ${ }^{5}$ Despite various health-related interventions, the reduction in infant mortality in the disadvantaged group has not been satisfactory.

There is a need to explore the factors that contribute to the diminished acceleration in the reduction of IMR. Knowledge about the cause of death and cause-specific contributions to infant mortality is important for selecting strategies to further reduce infant mortality.

In India where only $20 \%$ of deaths are medically certified and sick children are not 
brought outside home for medical care, ${ }^{6}$ the use of verbal autopsy (VA) to ascertain the cause of death has practical application. However, the utility of VA is limited by its inability to provide any insight into non-biological factors of infant death. It has been reported widely that social factors are important contributors to infant mortality. ${ }^{7-10}$ Thus, in order to substantially reduce infant mortality, social and health system causes need to be evaluated in addition to analysis of the cause of death.

Social autopsy (SA) can be an important tool for determining the non-biological factors of infant death, which include social, behavioural and health system determinants. ${ }^{11} \mathrm{SA}$ captures the dynamics of events preceding the death and includes factors related to home conditions, transport and health systems using a three-delay model. ${ }^{12}$ The health system and social factors may vary between geographical regions, and an in-depth analysis in local context of these factors through SA is required for decentralised action. Despite its importance, this tool has not been widely used in health settings with only limited literature available, mostly from African, Latin American and South Asian countries. ${ }^{11}{ }^{13-15}$ We have used the threedelay model to present SA data, where delay at level 1 was defined as delay in identification of danger signs and decision making to seek care, delay at level 2 as delay in reaching a health facility from home, and delay at level 3 as delay in getting healthcare at the health facility.

We conducted this study using VA and SA tools to identify the medical causes of death and the contribution of non-biological factors to infant mortality

\section{METHODS}

\section{Study setting}

The retrospective analysis of routinely collected VA and SA data was conducted in Ballabgarh Health and Demographic Surveillance System (HDSS) site located in Faridabad district of Haryana, North India. This site is also known as Comprehensive Rural Health Services Project (CRHSP), Ballabgarh. ${ }^{16}$ The HDSS, comprising 28 villages and nearly 93000 individuals (as at December 2012), is under continuous health and demographic surveillance. Vital statistics, socioeconomic and health service utilisation-related data of every individual have been available in the computerised Health Management Information System (HMIS) at the site since $1988 .{ }^{17}$

\section{Maternal and child healthcare in the study area}

Maternal care in the area is provided through the network of one government-operated Sub District Hospital, two Primary Health Centres and 12 Sub Centres. Health workers and community health volunteers (called Accredited Social Health Activists; ASHAs) make routine domiciliary visits in the study area to identify pregnant women for early antenatal registration. First trimester registration in the study area is more than $90 \%$. The institutional delivery rate in the study area is nearly $95 \%$. Free ambulance services for pregnant women and sick newborn infants were introduced in the area in 2009. Home-based newborn care, in which ASHAs make 5-7 home visits during the first 1.5 months of life of the infant, was introduced in the study area in 2011. Routine domiciliary visits by ASHAs include identification and referral of sick infants according to the strategy of integrated management of neonatal and childhood illness (IMNCI), implemented in the study area since 2009 .

\section{Study tools and data sources}

Information used in this study was derived from two data sources: VA and SA.

\section{Verbal autopsy (VA)}

VA was done routinely for every death that occurred in the study area using validated short VA tools known as the Ballabgarh VA tool (BVAT) for neonates (0-28 days), children ( 29 days -5 years) and adults ( $>5$ years), details of which have been published previously. ${ }^{18} 19$ This tool was developed and validated at HDSS Ballabgarh. VA was performed by a health worker in the local language (Hindi) 2 weeks after death (to avoid disturbing the grieving family) but no later than 6 weeks (to reduce recall bias). The informant was either the parent or a caregiver who had information regarding the events preceding death. The BVAT contained sociodemographic details such as age, sex, caste, date of death, place of death, time of death, care seeking before death and a symptoms checklist. A single cause of death was assigned to independent review by two medical doctors, arbitrated by a third experienced doctor in case of disagreement. For quality assurance, randomly selected households were revisited by health supervisors and medical doctors. For the present analysis, VA data for all the infant deaths which occurred from 1 January 2008 to 31 December 2012 were included.

\section{Social autopsy (SA)}

To identify the delay in care which might have played a role whereby precious minutes were lost resulting in infant deaths, SA was performed using the INDEPTH-WHO SA tool for neonates and children, which was locally translated into Hindi..$^{21}$ The SA tool was administered by a medical doctor, observing the principles of VA regarding the timing and informant for the interview. This tool was based on a three-delay model. ${ }^{12}$ A delay was supposed to have occurred if, in the opinion of the reviewers, the delay seemed to have partially contributed to the death or if the delay was 'avoidable' by some action of either the caregiver or health professional. Delay at level 1 was defined as a delay in identification of danger signs and decision making to seek care. The factors attributed to level 1 delay are mainly related to the failure on the part of the caregiver to identify the symptoms that are classified as danger signs, and the consequent delay in deciding to seek care in a health facility. Delay at level 2 was defined as delay in reaching a health facility from home. The level 2 delay refers to the time lag between the 
Table 1 Infant, neonatal and post-neonatal mortality rates, 2008-2012, HDSS Ballabgarh

\begin{tabular}{|c|c|c|c|c|c|c|c|}
\hline Year & $\begin{array}{l}\text { Total live } \\
\text { births }\end{array}$ & $\begin{array}{l}\text { Infant } \\
\text { deaths }\end{array}$ & $\begin{array}{l}\text { Neonatal deaths } \\
\mathrm{N}(\%)\end{array}$ & $\begin{array}{l}\text { Post-neonatal deaths } \\
\text { N (\%) }\end{array}$ & $\begin{array}{l}\text { IMR/1000 live } \\
\text { births }\end{array}$ & $\begin{array}{l}\text { NNMR/1000 } \\
\text { live births }\end{array}$ & $\begin{array}{l}\text { PNMR/1000 } \\
\text { live births }\end{array}$ \\
\hline 2008 & 2260 & 95 & 48 (50.5) & $47(49.5)$ & 42.0 & 21.2 & 20.8 \\
\hline 2010 & 2276 & 116 & $58(50.0)$ & $58(50.0)$ & 51.0 & 25.5 & 25.5 \\
\hline 2011 & 2232 & 102 & 55 (53.9) & $47(46.1)$ & 45.7 & 24.6 & 21.1 \\
\hline
\end{tabular}

IMR, infant mortality rate; NNMR, neonatal mortality rate; PNMR, post-neonatal mortality rate.

time points when the caregiver decides to seek healthcare to the time point when the caregiver physically reaches the healthcare facility. Delay at level 3 was defined as the delay in getting healthcare at the health facility. Each death could be attributed to one or more level of delay or no delay at all. Categorisation of delay was done by two authors independently (PG and AKS). This was again confirmed by another experienced researcher (SKR). SA was conducted on a subsample of infant deaths limited to the 6-month period from 1 January 2012 to 31 June 2012.

\section{Data collection}

Caregivers of the deceased infants were approached for conducting VA. This procedure has been in practice since 2012 as a component of comprehensive healthcare. The SA component was introduced later on. The respondents had the option not to participate in this activity without any prejudice to their otherwise claim to health services offered by CRHSP. The data collected were stored in electronic format after removing all personal identifiers. Thus the VA and SA data could not be traced to any particular individual, ensuring the confidentiality of the data.

This secondary analysis of VA and SA data was approved by the Institutional Ethics Committee (IEC) of the All India Institute of Medical Sciences, New Delhi (IEC285/07.06.2016). All the personal identifiers were removed from the dataset before analysis.

\section{Analysis of data}

Descriptive analysis was done for cause of death data to derive the annual cause-specific mortality fraction. Descriptive analysis of timing of death for all the deaths and with respect to cause of death was performed. SA data were used to estimate the proportion of deaths that were preceded by delay and, if present, the type of delay. We explored the association between cause of death and the presence of delay and the level of delay. Analysis of the SA data is based on a small number of cases and therefore may have large variations. All statistical analyses were performed with STATA release 12.0 software (Stata Corp, College Station, Texas, USA).

\section{RESULTS}

Rate, causes and timing of death

From 2008 to 2012 a total of 514 infant deaths were recorded in the study area, of which 279 (54.3\%) were neonatal deaths and $235(45.7 \%)$ were post-neonatal deaths. The IMR and neonatal mortality rate (NNMR) during the 5-year study period was 46.5/1000 live births and 25.3/1000 live births, respectively. Gender-specific analysis revealed that the NNMR was the same for boys and girls, but girls had a higher IMR than boys (49.3 vs 44.2). In the year 2012, neonatal deaths accounted for nearly $70 \%$ of the infant deaths (table 1 ).

Among neonatal deaths, $39.0 \%$ of deaths occurred on the first day and $72.7 \%$ occurred during the first week (table 2).

The level of disagreement in initial coding of cause of death was $4.5 \%$ (23 deaths) and disagreement in all cases were arbitrated by a third investigator. The most common medical cause of neonatal deaths was birth asphyxia $(31.5 \%)$, followed by low birth weight (LBW)/

\begin{tabular}{llllll}
\hline \multicolumn{7}{l}{ Table 2} & Distribution of neonatal deaths by day of death, 2008-2012, HDSS Ballabgarh & & \\
Year & $\begin{array}{l}\text { Day 1 } \\
\text { N (\%) }\end{array}$ & $\begin{array}{l}\text { Days 2-7 } \\
\text { N (\%) }\end{array}$ & $\begin{array}{l}\text { Days 8-14 } \\
\text { N (\%) }\end{array}$ & $\begin{array}{l}\text { Days 15-28 } \\
\text { N (\%) }\end{array}$ & $\begin{array}{l}\text { Total } \\
\text { N (\%) }\end{array}$ \\
\hline 2008 & $17(35.4)$ & $15(31.2)$ & $7(14.6)$ & $9(18.7)$ & $48(100)$ \\
2009 & $22(40.0)$ & $18(32.7)$ & $7(12.7)$ & $8(14.5)$ & $55(100)$ \\
2010 & $24(41.8)$ & $20(34.5)$ & $9(15.5)$ & $5(8.6)$ & $58(100)$ \\
2011 & $16(29.1)$ & $19(34.5)$ & $8(14.5)$ & $12(21.8)$ & $55(100)$ \\
2012 & $30(47.7)$ & $22(34.9)$ & $6(9.5)$ & $5(7.9)$ & $63(100)$ \\
Total & $109(39.0)$ & $94(33.7)$ & $37(13.3)$ & $39(14.0)$ & $279(100)$ \\
\hline
\end{tabular}


Table 3 Cause-specific mortality fraction of infant deaths (overall and stratified by sex), 2008-2012, HDSS Ballabgarh

\begin{tabular}{llll}
\hline Cause of death & $\begin{array}{l}\text { Total } \\
\text { N (\%) }\end{array}$ & $\begin{array}{l}\text { Boys } \\
\text { N (\%) }\end{array}$ & $\begin{array}{l}\text { Girls } \\
\text { N (\%) }\end{array}$ \\
\hline Birth asphyxia and birth injuries & $98(19.1)$ & $55(20.8)$ & $43(17.2)$ \\
\hline Pneumonia & $88(17.1)$ & $53(20.1)$ & $35(14.0)$ \\
\hline Low birth weight/prematurity & $84(16.3)$ & $41(15.5)$ & $43(17.2)$ \\
\hline Other infection and sepsis & $59(11.5)$ & $30(11.4)$ & $29(11.6)$ \\
\hline Diarrhoea & $40(7.8)$ & $8(3.0)$ & $32(12.8)$ \\
Congenital malformation & $40(7.8)$ & $26(9.8)$ & $14(5.6)$ \\
\hline Other perinatal causes & $12(2.3)$ & $7(2.6)$ & $5(2.0)$ \\
Sudden infant death syndrome & $28(5.4)$ & $11(4.2)$ & $17(6.8)$ \\
\hline Not identified & $9(1.7)$ & $5(1.9)$ & $4(1.6)$ \\
\hline Others & $56(11.1)$ & $28(10.6)$ & $28(11.2)$ \\
\hline Total & $514(100)$ & $264(100)$ & $250(100)$ \\
\hline
\end{tabular}

prematurity $(26.5 \%)$ and pneumonia and other infections $(16.9 \%)$. Analysis by gender showed that girls were more predisposed to death due to diarrhoea than boys (table 3).

Among post-neonatal deaths, different kind of infections caused more than half of the deaths (pneumonia, 28.9\%; other infection and sepsis, $13.6 \%$; diarrhoea, $15.3 \%$; figure 1 )

Analysis of the time of death with respect to the cause of neonatal death revealed that $60 \%$ and $90 \%$ of deaths due to birth asphyxia occurred on the first day and first week of life, respectively (figure 2).

\section{Delay in care}

Of 52 infant deaths that occurred between July 2012 and December 2012, SA could be done for 51 (34 neonatal deaths and 17 post-neonatal deaths). All the informants reported having recognised severe or possibly severe symptoms or were told by the treating doctor in the case of neonates. Nearly $75 \%$ of the infants $(n=38)$ received care, or their caretakers sought or tried to seek care or were already seeking care at the institution after birth, whereas $15.7 \%$ infants died immediately after birth. No care was sought or provided for $9.8 \%$ of infants. Of those who sought care, the majority $(94.7 \%)$ went for outside care. However, only informal care was sought or given for $19.4 \%$ of infants. Out of $29(80.5 \%)$ who sought or tried to seek formal care, three died on the way to hospital and 26 were able to seek care. Almost half $(46.2 \%)$ were treated and referred to a higher health facility but $41.7 \%$ of them chose to return home rather than accepting a referral. Figure 3 shows the breakdown in the pathway to survival that could have possibly led to death of the infants.

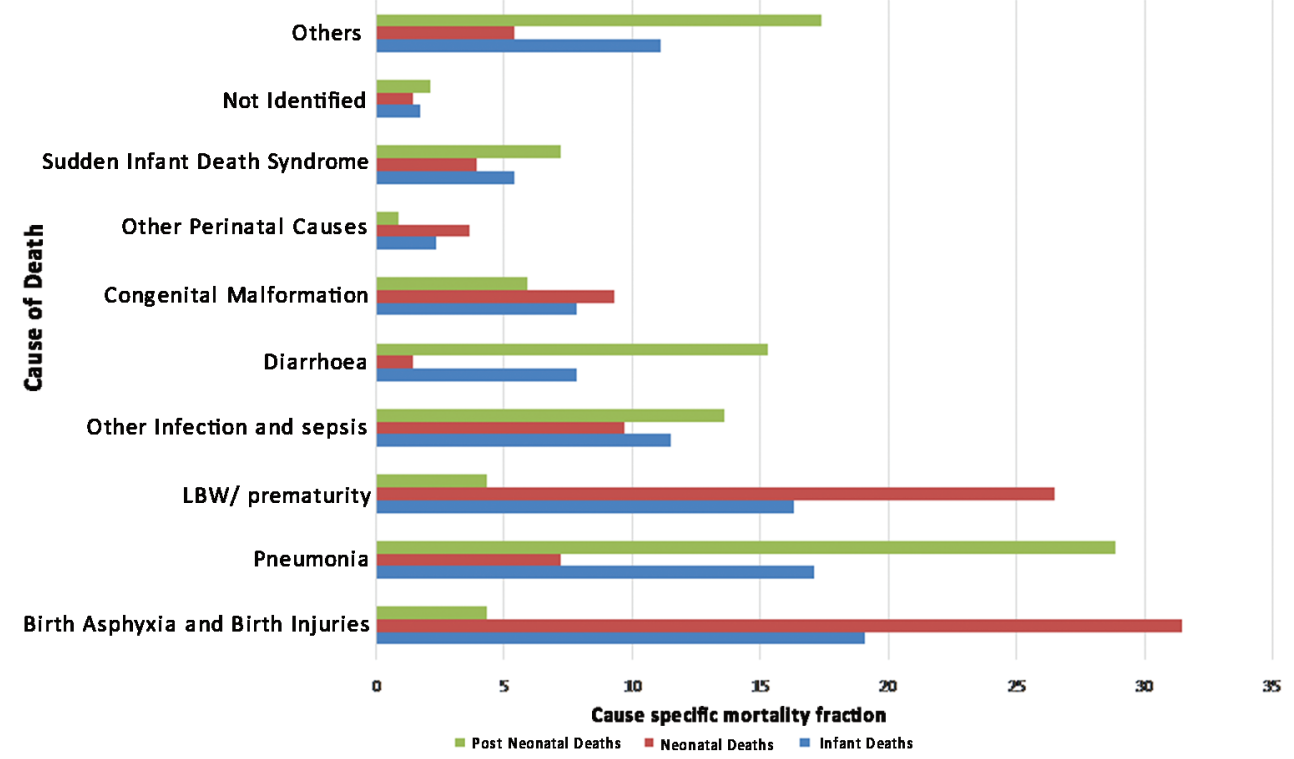

Figure 1 Cause-specific mortality fraction of infant, neonatal and post-neonatal deaths, 2008-2012, HDSS Ballabgarh. 
TIMING OF NEONATAL DEATH (OVERALL AND CAUSE WISE)

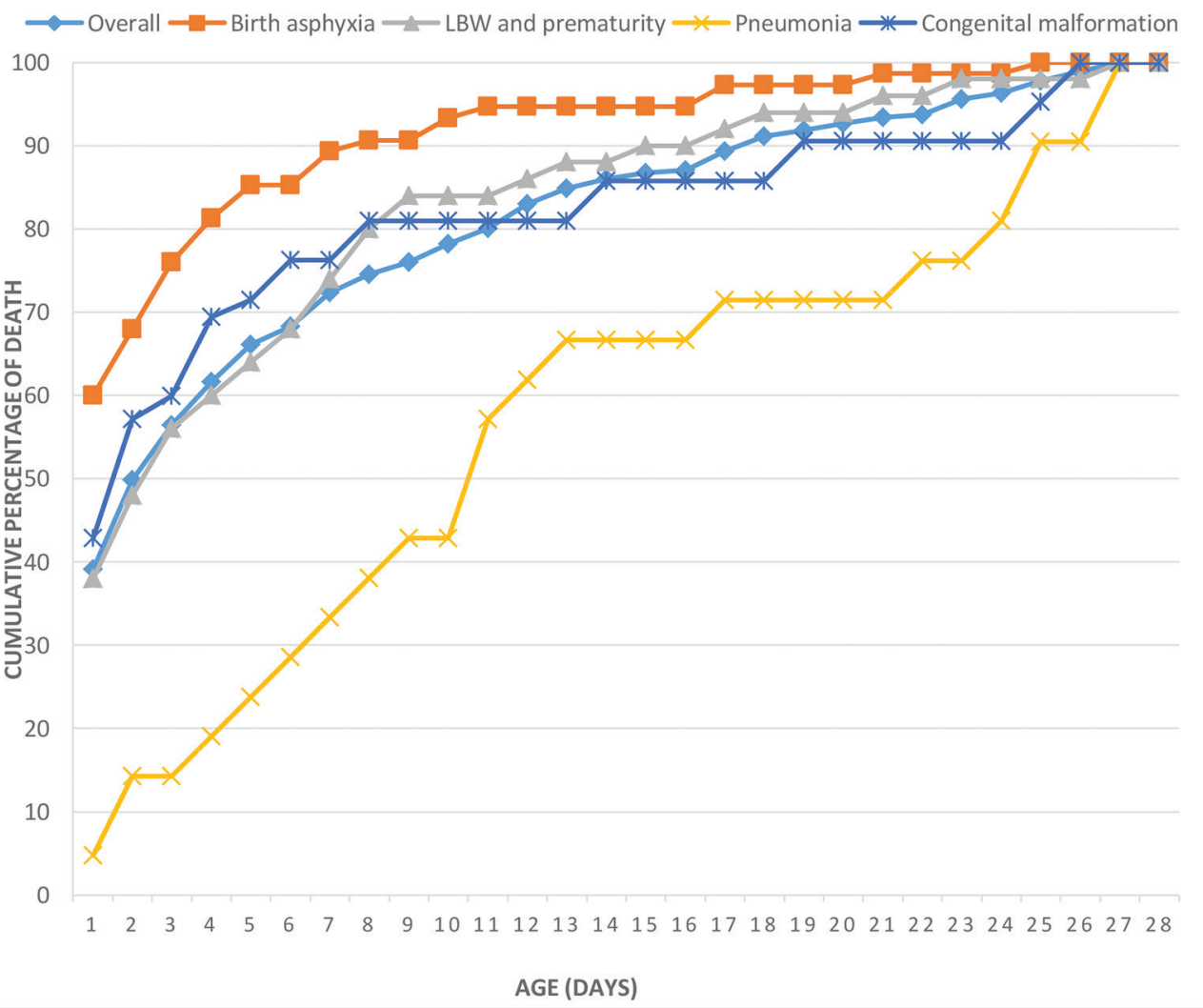

Figure 2 Distribution of cumulative percentage of neonatal deaths (all-cause and cause-specific) by day of neonatal death.

Delay was not observed at any level in 24 (47\%) deaths. Delay levels 1, 2 and 3 were reported among 14 (27.5\%), $4(7.8 \%)$ and $4(7.8 \%)$ deaths, respectively (table 4$)$.

We analysed the level of delay with respect to the cause of death. Among neonatal deaths, when no delay was observed the most common cause of death was congenital malformation and birth asphyxia. LBW/prematurity was the most common cause of death where there was delay at level 1 (figure 4). Among post-neonatal deaths, since infection and sudden infant death syndrome were responsible for almost all the deaths, we did not attempt to analyse the relationship between cause of death and delay due to very small numbers.

\section{DISCUSSION}

VA and SA tools have predominantly been used in African and Asian countries to quantify the causes of death and identify social contributors among neonates and infants. Studies done in Kenya, Ghana, Niger and Uganda have shown that synthesis of VA and SA data for decision making had a high impact on designing effective child survival interventions. ${ }^{22-25}$ Niger has recently adopted the use of VA and SA and its integration with a national Health Management Information System. ${ }^{26}$ In India, too, evidence from VA and SA data has the potential to inform policymakers to design strategies for further reduction in infant mortality.

The present study has described the causes of and contributors to infant mortality using VA and SA data. The proportion of neonatal deaths out of all infant deaths was less in our study (54\%) than in a large multicentre study of 2218 infant deaths in five rural sites of India $(70 \%) .{ }^{27}$ However, in our study the proportion of neonatal deaths also reached nearly $70 \%$ in year 2012 , which was nearly $50 \%$ in the preceding 3 years. Comparison of the fraction of neonatal deaths out of total infant deaths requires cautious interpretation. The prevailing IMR in the study area needs to be put into context before any such comparison is made as, when overall infant mortality decreases, causes predominantly responsible for post-neonatal deaths tend to recede first. We also found girls to be at a disadvantage compared with boys with respect to infant mortality. The disadvantage was not appreciated for neonatal mortality, suggesting differentials in environmental factors and the health-seeking process rather than inherent biological differences between the sexes. This pattern is similar to other studies from India and Bangladesh. ${ }^{28}{ }^{29}$ However, further studies are needed to identify factors and possible solutions to address this. 


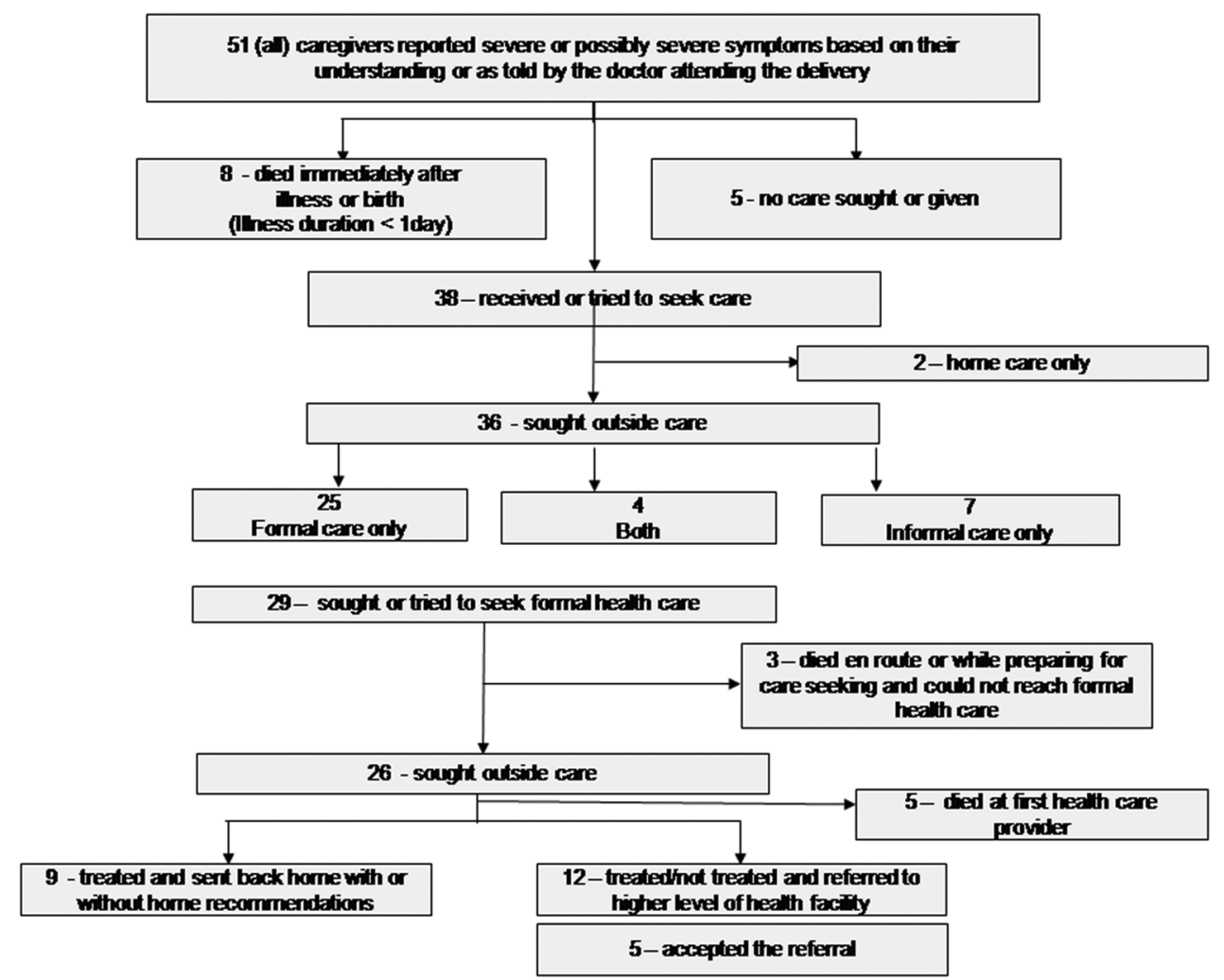

Figure 3 The 'Pathway to Survival' for 51 deceased infants, July to December 2012, HDSS Ballabgarh.

The medical causes of neonatal deaths and post-neonatal deaths remained almost unchanged over the 5-year period for which data were analysed. Birth asphyxia $(31 \%)$ and LBW/prematurity $(26.5 \%)$ were the most important causes of neonatal mortality, followed by sepsis or pneumonia $(16.9 \%)$ and congenital anomaly $(9.3 \%)$. A study done in rural north India using VA found that preterm birth $(27 \%)$ was the most common cause of death followed by sepsis or pneumonia $(24 \%)$ and birth asphyxia (14\%). ${ }^{30}$ Congenital anomaly was the cause of death in $6.5 \%$ of cases. In this study, among $22.8 \%$ of neonatal deaths the cause of death could not be identified, in comparison with $1.4 \%$ in our study. A systematic review was done to obtain the median proportion of cause of deaths from studies published in India from
1985 to $2008 .^{31}$ This study reported preterm birth to have a median proportion of $27 \%$ among neonatal deaths, followed by sepsis and pneumonia (24\%) and birth asphyxia (14\%). Thus, in our study, birth asphyxia and congenital malformation was reported to cause a higher proportion of deaths than was reported by these two studies. The proportion of deaths due to sepsis or pneumonia was less in our study but the proportion of deaths due to prematurity was almost similar to other previous reports. When overall mortality decreases, the proportion of deaths due to easily preventable causes such as sepsis or pneumonia, for which effective interventions are available, declines first. Further decline is followed by those caused by congenital malformation and birth asphyxia which need more skilled intranatal care and diagnostic

Table 4 Distribution of level of delay for infant, neonatal and post-neonatal deaths, July to December 2012, HDSS Ballabgarh

\begin{tabular}{|c|c|c|c|c|c|c|}
\hline \multirow[b]{2}{*}{ Level of delay } & \multicolumn{2}{|c|}{ Infant } & \multicolumn{2}{|c|}{ Neonatal } & \multicolumn{2}{|c|}{ Post-neonatal } \\
\hline & $\mathbf{N}$ & $\%$ & $\mathbf{N}$ & $\%$ & $\mathbf{N}$ & $\%$ \\
\hline No delay & 24 & 47.1 & 17 & 50.0 & 7 & 41.2 \\
\hline Level 1 & 14 & 27.5 & 11 & 32.4 & 3 & 17.6 \\
\hline Level 2 & 4 & 7.8 & 1 & 2.9 & 3 & 17.6 \\
\hline Levels $1+2$ & 1 & 2.0 & 0 & 0.0 & 1 & 5.9 \\
\hline Level 3 & 4 & 7.8 & 3 & 8.8 & 1 & 5.9 \\
\hline Levels $2+3$ & 3 & 5.9 & 2 & 5.9 & 1 & 5.9 \\
\hline Level $1+2+3$ & 1 & 2.0 & 0 & 0.0 & 1 & 5.9 \\
\hline Total & 51 & 100 & 34 & 100 & 17 & 100 \\
\hline
\end{tabular}




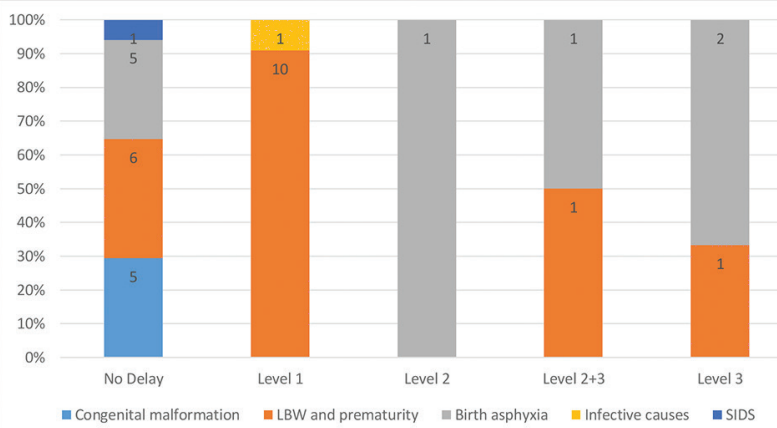

Figure 4 Distribution of cause of neonatal deaths with respect to level of delay, July to December 2012, HDSS Ballabgarh.

availability for congenital malformations. Thus, during the initial decline in mortality rates the proportion of deaths due to congenital malformation and birth asphyxia tends to increase. However, between-study comparisons require careful consideration of methodological differences in estimating the cause of death. The systematic review included studies using VA as well as other methods for estimation of the proportional contribution of causes of death. ${ }^{31}$ No significant difference was seen when the proportional contribution of causes reported from VA was compared with studies adopting other methods. Still, there is a need to emphasise the element of subjectivity which exists in assigning cause of death among infants using VA. Difficulty in ascertaining death due to birth asphyxia and distinguishing it from other causes has been reported previously in some validation studies. ${ }^{32} \mathrm{VA}$ has limited validation while assigning a cause to death followed by symptoms of sepsis and respiratory illness, particularly pneumonia, as most times the symptoms are non-specific. ${ }^{33}$ The misclassification of cause of death, apart from heterogeneity among study setting, can have an overall impact on cause-specific mortality fraction. ${ }^{34}$

We have also reported the timing of neonatal death, both aggregate and by cause of death. A total of 39\% of neonatal deaths occurred on the first day of life and $72.7 \%$ occurred during the first 7 days of life. Previous estimates from India have reported a range of 31.8-44\% of neonatal deaths occurring on the first day and $66-75 \%$ within the first week. ${ }^{27}{ }^{30}{ }^{35-37}$ We analysed information on cause of death by timing of neonatal death, which has not been addressed adequately in the literature for the Indian setting. In our study, $60 \%$ of deaths due to birth asphyxia occurred on the first day of life and $90 \%$ occurred within 7 days of life. This information from India is available only in one study by Baqui et $a l^{30}$ which reported that $60 \%$ of deaths due to birth asphyxia occurred on the first day of life and all the deaths due to birth asphyxia occurred within 7 days of life. The overall fraction and timing of death due to birth asphyxia calls for effective interventions targeted towards quality intrapartum care. Despite an increase in the institutional delivery rate in the area (from $70 \%$ to $85 \%$ during the study period), the proportion of deaths due to birth asphyxia has remained high and almost unchanged over the years. It has been documented that access to emergency obstetric services is necessary to reduce neonatal mortality, particularly by targeting deaths due to birth asphyxia. ${ }^{38}$ Reports suggest a lack of necessary skills among healthcare providers in primary healthcare settings in low and middle income countries including India. ${ }^{39-41}$ Thus, in settings with a high institutional delivery rate, the way forward to reduce deaths due to birth asphyxia would be capacity building of the healthcare providers and health system strengthening.

Of all the deaths caused by LBW/prematurity, more than $70 \%$ occurred during the first week of life, highlighting the importance of continuum of care starting from the early antenatal period to the early neonatal period. Baqui et al reported $70 \%$ of deaths due to LBW/ prematurity occurred during the first 7 days of life. ${ }^{30}$ Evidence suggests that improving the nutritional status of pregnant women, adequately spaced deliveries, increasing the age of first delivery and prevention and treatment of urinary tract infections can help to prevent preterm births and improved care of LBW and preterm births through vitamin A supplementation, promotion of early breast feeding, prevention and management of hypothermia including kangaroo mother care can enhance their chances of survival. ${ }^{42-48}$ Although intensive efforts were made in the study area in terms of identification of pregnancy, care during antenatal visits including nutritional counselling, and identification, referral and follow-up of high-risk pregnancies during antenatal contacts, the high proportion of deaths due to LBW/prematurity calls for augmented action.

During the post-neonatal period, infective causes were responsible for nearly $60 \%$ of post-neonatal deaths with pneumonia $(28.9 \%)$, diarrhoea $(15.3 \%)$ and other infection and sepsis $(13.6 \%)$ as the most important causes. A similar pattern was also observed in previous publications from India with minor differences. ${ }^{4-52}$ Even in the neonatal period, pneumonia or sepsis were responsible for $24 \%$ of deaths, highlighting the importance of proper implementation of IMNCI and other similar strategies. Although in controlled settings the effect of IMNCI on neonatal and under five mortality was significant, its implementation has remained dismal. ${ }^{53-56}$ In our study area, implementation of IMNCI was not satisfactory with only $10 \%$ of expected cases of acute respiratory infections and diarrhoea being reported by health workers under IMNCI reporting (unpublished information). Effort is needed to continuously reduce deaths caused by infectious diseases, particularly for post-neonatal infants. There is a need to properly implement IMNCI strategy for early identification and prompt referral of children with pneumonia, diarrhoea and other infective causes.

To complement the findings of VA, we also performed SA on a subsample of infant deaths. Analysis of SA data revealed that delay at any level was observed in $50 \%$ of neonatal deaths and $41 \%$ of post-neonatal deaths. A SA study performed among neonates in the same setting in 
2009 found any level of delay to be present in $74 \%$ of deaths. ${ }^{37}$ Although the proportion of delay at levels 1 and 3 were almost the same, there was a large reduction in delay at level 2 in this study compared with the previous study. An overall reduction in any level of delay could be due to implementation of new child health interventions in the area between 2009 and 2012, whereas the major reduction in delay at level 2 could largely be attributed to the introduction of free ambulance services for pregnant women and sick neonates in the study area from 2009 onwards. Similarly, for post-neonatal deaths, another study done in 16 districts of eight states in 2005-6 showed a high proportion of delay at level $1(42.3 \%)$ and level 2 $(46.0 \%) .{ }^{57}$ The lesser delay observed in the present study compared with these two studies may be due to improved child survival efforts, strengthening of the health system and the referral transport system over the years. Probably for the first time, we have reported the level of delay with respect to cause of neonatal death. Most deaths due to congenital anomaly and birth asphyxia were not associated with any level of delay. Nearly $80 \%$ of births took place in hospital and the majority of deaths due to birth asphyxia and congenital anomaly happened during the first few days of life, which precludes the eventuality of delay at levels 1 and 2 . This finding underlines the importance of focusing on in utero detection of congenital anomalies and health system strengthening. The importance of strengthening the health system is further substantiated by the fact that the majority of deaths due to these causes occurred during the early neonatal period. Since the majority of births occurred at a health facility, increasing the work force at the peripheral level for newborn care, capacity building through sustained training programmes and continuous supportive supervision, provision of adequate newborn care centres as the norm with adequate supplies, equipment and workforce would be fruitful. Deaths due to LBW/prematurity were mostly followed by delay at level 1 , which suggests that caregivers failed to recognise the danger signs related to prematurity and its consequences such as hypothermia and feeding problems. Thus, we need to enhance homebased newborn care, which has been shown to improve mothers' knowledge regarding danger signs and subsequent healthcare seeking. ${ }^{58}$ Nevertheless, narratives available in VA forms showed the presence of vague symptoms rather than clearcut danger signs before neonatal deaths in many cases, which highlights the importance of routine preventive care of all neonates rather than care of only sick neonates.

\section{Strengths and limitations of the study}

This study has certain strengths. To the best of our knowledge, this is the first study from India to include both VA and SA data for infant deaths. These two tools used collectively can provide better insights into the complexities of infant death. Thus, we have explored both biological causes and community and health system issues leading to infant death. The study included a large 5-year birth cohort comprising nearly 11000 births. The site was under continuous health and demographic surveillance with negligible missing information on births and deaths. Also, the cause of death assignment in this setting has been done for the last 20 years and health workers were adequately trained to capture data on the cause of death. SA was administered by a medical doctor specialising in community health, so the validity of the data is likely to be high. Hence, the findings of this study could be generalised to north Indian settings with a similar child mortality pattern, health infrastructure and social structure.

However, this study also had some limitations. Our sampling frame for SA was very small and was limited to only 51 infant deaths which occurred during the last 6 months of the study period. Variations are possible in estimation of the proportion of levels of delay. We could not attempt any exploratory analysis except for cause of death with respect to level of delay due to the limited number of deaths for each level of delay. The present study highlighted the social causes related to delay in care seeking. There could be some other social contributors of infant mortality which have not been explored in this study. Another limitation could be due to recall problems. Although all the interviews were made between 2 and 6 weeks after the infant death, recall problems could not be completely ruled out.

\section{CONCLUSION}

Birth asphyxia, LBW/prematurity and infections remain the main causes of infant mortality. Level 1 delay (ie, failure to recognise the danger sign) was present in almost half of all deaths. Routine preventive care of all neonates rather than care of only sick neonates is therefore required, maybe through enhanced home-based care. SA data along with VA data should be routinely captured to have a better insight of the dynamics related to infant death and to make appropriate interventions.

Acknowledgements This paper was first presented at the INDEPTH Scientific Conference 2015 in Addis Ababa, Ethiopia on 11-13 November 2015. INDEPTH provided a travel award to SKR for participation at the conference. We would also like to thank the participants of this study and the entire population residing in HDSS Ballabgarh area.

Contributors SKR, SK, PM and CSP conceived and designed the study. AKS, RS and PG acquired and analysed the data and prepared the initial manuscript. SKR, SK, PM and CSP revised the draft critically. All authors have read and approved the final manuscript. All authors agree to be accountable for all aspects of the work in ensuring that questions related to the accuracy or integrity of any part of the work are appropriately investigated and resolved.

Competing interests None declared.

Ethics approval Institute Ethics Committee, All India Institute of Medical Sciences, New Delhi, India.

Provenance and peer review Not commissioned; externally peer reviewed. Data sharing statement Extra data can be accessed via the Dryad data repository at

Open Access This is an 0pen Access article distributed in accordance with the Creative Commons Attribution Non Commercial (CC BY-NC 4.0) license, which permits others to distribute, remix, adapt, build upon this work non-commercially, 
and license their derivative works on different terms, provided the original work is properly cited and the use is non-commercial. See: http://creativecommons.org/ licenses/by-nc/4.0/

(C) Article author(s) (or their employer(s) unless otherwise stated in the text of the article) 2017. All rights reserved. No commercial use is permitted unless otherwise expressly granted.

\section{REFERENCES}

1. You D, Hug L, Ejdemyr S, et al. Global, regional, and national levels and trends in under-5 mortality between 1990 and 2015, with scenario-based projections to 2030: a systematic analysis by the UN Inter-agency group for Child Mortality estimation. Lancet 2015;:S01406736:00120-8.

2. World Health Organization. Children: Reducing mortality fact sheet 178. Geneva, Switzerland: World Health Organization, 2014. http:// www.who.int/mediacentre/factsheets/fs178/en/. (accessed 5 May 2016).

3. Registrar General of India. Sample Registration System. New Delhi: Office of the Registrar General of India, 2000.

4. Registrar General of India. Sample Registration System. New Delhi : Office of the Registrar General of India, 2008.

5. Registrar General of India. Sample Registration System. New Delhi: Office of the Registrar General of India, 2016.

6. Registrar General of India. Medically-certified causes of death, statistical report: 2013. New Delhi: Government of India 2015.

7. Nguyen $\mathrm{KH}$, Jimenez-Soto $\mathrm{E}$, Morgan A, et al. How does progress towards the MDG 4 affect inequalities between different subpopulations? Evidence from Nepal. J Epidemiol Community Health 2013;67:311-9.

8. Musafili A, Essén B, Baribwira C, et al. Trends and social differentials in child mortality in Rwanda 1990-2010: results from three demographic and health surveys. J Epidemiol Community Health 2015;69:834-40.

9. Sreeramareddy CT, Harsha Kumar HN, Sathian B. Time trends and inequalities of under-five mortality in Nepal: a secondary data analysis of four demographic and health surveys between 1996 and 2011. PLoS One 2013;8:e79818.

10. Singh-Manoux A, Dugravot A, Smith GD, et al. Adult education and child mortality in India: the influence of caste, household wealth, and urbanization. Epidemiology 2008;19:294-301.

11. Kalter HD, Salgado R, Babille M, et al. Social autopsy for maternal and child deaths: a comprehensive literature review to examine the concept and the development of the method. Popul Health Metr 2011;9:45.

12. Thaddeus $S$, Maine $D$. Too far to walk: maternal mortality in context. Soc Sci Med 1994;38:1091-110.

13. Nonyane BA, Kazmi N, Koffi AK, et al. Factors associated with delay in care-seeking for fatal neonatal illness in the Sylhet district of Bangladesh: results from a verbal and social autopsy study. J Glob Health 2016;6:010605.

14. Kalter HD, Yaroh AG, Maina A, et al. Verbal/social autopsy study helps explain the lack of decrease in neonatal mortality in Niger, 2007-2010. J Glob Health 2016;6:010604.

15. Koffi AK, Maina A, Yaroh AG, et al. Social determinants of child mortality in Niger: results from the 2012 National Verbal and Social Autopsy Study. J Glob Health 2016;6:010603.

16. Kant S, Misra P, Gupta S, et al. The Ballabgarh Health and Demographic Surveillance System (CRHSP-AIIMS). Int J Epidemio 2013;42:758-68.

17. Krishnan A, Nongkynrih B, Yadav K, et al. Evaluation of computerized health management information system for primary health care in rural India. BMC Health Serv Res 2010;10:310.

18. Krishnan A, Kumar R, Nongkynrih B, et al. Adult mortality surveillance by routine health workers using a short verbal autopsy tool in rural north India. J Epidemiol Community Health 2012;66:501-6.

19. Kumar R, Kapoor SK, Krishnan A. Performance of cause-specific childhood mortality surveillance by health workers using a short verbal autopsy tool. WHO South-East Asia J Publ Health 2012;1:151-8.

20. INDEPTH Network. Social autopsy tool for newborn deaths (028 days): an INDEPTH tool. INDEPTH Network, Accra, Ghana. 2012 http://www.indepthnetwork.org/tools/New\%20INDEPTH\% 20newborn\%20SA\%20tool.pdf (accessed 5 May 2016).

21. INDEPTH Network. Social autopsy tool for child deaths (29 days-5 years): an INDEPTH tool. INDEPTH Network, Accra, Ghana. 2012 http://www.indepthnetwork.org/tools/New\%20INDEPTH\%20child\% 20SA\%20tool.pdf (accessed 5 May 2016).
22. Nutley T, McNabb S, Salentine S. Impact of a decision-support tool on decision making at the district level in Kenya. Health Res Policy Syst 2013;11:34.

23. Gutiérrez $\mathrm{G}$, Reyes $\mathrm{H}$, Martínez $\mathrm{H}$, et al. Study of the disease-health seeking-death process: another use of the verbal autopsy. Int $J$ Epidemiol 1994;23:427-8.

24. Schumacher R, Swedberg E, Diallo MO, et al. Mortality study in Guinea: investigating the causes of death for children under 5 . The Basic Support for Institutionalizing Child Survival project (BASICS II). Arlington, VA 2002http://www.basics.org/documents/pdf/guinea mort.pdf.

25. Källander K, Kadobera D, Williams TN, et al. Social autopsy: INDEPTH network experiences of utility, process, practices, and challenges in investigating causes and contributors to mortality. Popul Health Metr 2011;9:44.

26. Bensaïd K, Yaroh AG, Kalter HD, et al. Verbal/social autopsy in Niger 2012-2013: a new tool for a better understanding of the neonatal and child mortality situation. J Glob Health 2016;6:010602.

27. ICMR Young Infant Study Group. Age profile of neonatal deaths. Indian Pediatr 2008;45:991-4

28. Krishnan A, Nawi NG, Byass $P$, et al. Sex-specific trends in under-five mortality in rural Ballabgarh. Indian Pediatr 2014;51:48-51.

29. Fauveau V, Koenig MA, Wojtyniak B. Excess female deaths among rural Bangladeshi children: an examination of cause-specific mortality and morbidity. Int J Epidemiol 1991;20:729-35.

30. Baqui $A H$, Darmstadt GL, Williams EK, et al. Rates, timing and causes of neonatal deaths in rural India: implications for neonatal health programmes. Bull World Health Organ 2006;84:706-13.

31. Lahariya C, Sudfeld CR, Lahariya D, et al. Causes of child deaths in India, 1985-2008: a systematic review of literature. Indian J Pediatr 2010;77:1303-11.

32. Marsh DR, Sadruddin S, Fikree FF, et al. Validation of verbal autopsy to determine the cause of 137 neonatal deaths in Karachi, Pakistan. Paediatr Perinat Epidemiol 2003;17:132-42.

33. Kalter HD, Hossain M, Burnham G, et al. Validation of caregiver interviews to diagnose common causes of severe neonatal illness. Paediatr Perinat Epidemiol 1999;13:99-113.

34. Anker M. The effect of misclassification error on reported causespecific mortality fractions from verbal autopsy. Int J Epidemiol 1997;26:1090-6

35. Bapat U, Alcock G, More NS, et al. Stillbirths and newborn deaths in slum settlements in Mumbai, India: a prospective verbal autopsy study. BMC Pregnancy Childbirth 2012;12:39.

36. Niswade A, Zodpey SP, Ughade S, et al. Neonatal morbidity and mortality in tribal and rural communities in central India. Indian $J$ Community Med 2011;36:150-8.

37. Upadhyay RP, Rai SK, Krishnan A. Using three delays model to understand the social factors responsible for neonatal deaths in rural Haryana, India. J Trop Pediatr 2013;59:100-5.

38. Rammohan A, lqbal K, Awofeso N, et al. Reducing neonatal mortality in India: critical role of access to emergency obstetric care. PLoS One 2013;8:e57244.

39. Malhotra S, Zodpey SP, Vidyasagaran AL, et al. Assessment of essential newborn care services in secondary-level facilities from two districts of India. J Health Popul Nutr 2014;32:130-41.

40. Ariff S, Soofi SB, Sadiq K, et al. Evaluation of health workforce competence in maternal and neonatal issues in public health sector of Pakistan: an assessment of their training needs. BMC Health Serv Res 2010;10:319.

41. Monebenimp F, Tenefopa M, Mve Koh V, et al. Competence of health care providers on care of newborns at birth in a level-1 health facility in Yaoundé, Cameroon. Pan Afr Med J 2012;11:45.

42. WHO Collaborative Study Team on the Role of Breastfeeding on the Prevention of Infant Mortality. Effect of breastfeeding on infant and child mortality due to infectious diseases in less developed countries: a pooled analysis. Lancet 2000;355:451-5.

43. Quasem I, Sloan NL, Chowdhury A, et al. Adaptation of kangaroo mother care for community-based application. J Perinatol 2003;23:646-51.

44. Kapoor SK, Kumar G, Pandav CS, et al. Incidence of low birth weight in rural Ballabgarh, Haryana. Indian Pediatr 2001;38:271-5.

45. Kramer MS. Determinants of low birth weight: methodological assessment and meta-analysis. Bull World Health Organ 1987:65:663-737.

46. Defo BK, Partin M. Determinants of low birthweight: a comparative study. J Biosoc Sci 1993;25:87-100.

47. Metgud CS, Naik VA, Mallapur MD. Factors affecting birth weight of a newborn--a community based study in rural Karnataka, India. PLoS One 2012; 7:e40040. 
48. Rao T, Aggarwal AK, Kumar R. Dietary Intake in third trimester of pregnancy and prevalence of LBW: a community-based study in a rural area of Haryana. Indian J Community Med 2007;32:272-6.

49. Vaid A, Mammen A, Primrose B, et al. Infant mortality in an urban slum. Indian J Pediatr 2007;74:449-53.

50. Hirve S, Ganatra B. A prospective cohort study on the survival experience of under five children in rural western India. Indian Pediatr 1997;34:995-1001.

51. Tandon BN, Sahai A, Balaji LN, et al. Morbidity pattern and cause specific mortality during infancy in ICDS projects. $J$ Trop Pediatr 1987;33:190-3.

52. Singhal PK, Mathur GP, Mathur S, et al. Mortality patterns in under six children in I.C.D.S. urban slum. Indian Pediatr 1986;23:617-22.

53. Bhandari N, Mazumder S, Taneja S, et al. Effect of implementation of Integrated Management of Neonatal and Childhood IIIness (IMNCI) programme on neonatal and infant mortality: cluster randomised controlled trial. BMJ 2012;344:e1634.
54. Biswas AB, Mukhopadhyay DK, Mandal NK, et al. Skill of frontline workers implementing integrated management of neonatal and childhood illness: experience from a district of West Bengal, India. $J$ Trop Pediatr 2011:57:352-6.

55. Mohan P, Kishore B, Singh S, et al. Assessment of implementation of integrated management of neonatal and childhood illness in India. $J$ Health Popul Nutr 2011;29:629-38.

56. Shewade HD, Aggarwal AK, Bharti B. Integrated Management of Neonatal and Childhood IIIness (IMNCI): skill assessment of health and Integrated Child Development Scheme (ICDS) workers to classify sick under-five children. Indian J Pediatr 2013;80:448-54.

57. Deshmukh V, Lahariya C, Krishnamurthy S, et al. Taken to health care provider or not, under-five children die of preventable causes: findings from cross-sectional survey and social autopsy in rural India. Indian J Community Med 2016;41:108-19.

58. Dongre AR, Deshmukh PR, Garg BS. A community based approach to improve health care seeking for newborn danger signs in rural Wardha, India. Indian J Pediatr 2009;76:45-50. 